\title{
Codesign e Economia Solidária: construindo identidades com grupos produtivos no Maranhão
}

Ferdinan Silva de Sousa;

Sâmio Lucas Pachêco Barbosa;

Raquel Gomes Noronha

Resumo: Este artigo apresenta o processo de contextualização, criatividade e colaboração entre o Núcleo de Pesquisas em Inovação, Design e Antropologia (NIDA-UFMA), a Fundação Grupo Esquel Brasil e a Secretaria do Trabalho e Economia Solidária (SETRES) com grupos produtivos do Maranhão (41 grupos e o Centro de Referência em Economia Solidária - CRESOL). O trabalho de pesquisa foi realizado em parceria com o projeto Maranhão Desenvolvido Mais Justo e Solidário (promovido pelo governo do estado do Maranhão), com o objetivo de fortalecer e articular pequenos empreendimentos com viés econômico e solidário. Por meio de visitas e oficinas presenciais com os envolvidos, utilizando ferramentas como a estrela de valor, benchmarking e desenhos coletivos, a experiência traz resultados sobre a tangibilização de identidades culturais para identidades visuais, o reconhecimento do saber tradicional como percurso projetual, assim como considerações sobre codesign e economia solidária, promovendo qualidade de vida, sustentabilidade e oportunidades a territórios que possuem tradições e saberes diversos.

Palavras-Chave: Codesign; Economia Solidária; Criatividade; Maranhão. 


\section{Introdução}

Muitas comunidades utilizam do conhecimento cultural, histórico e ambiental de seus territórios para inspirar e transformar materiais locais em produtos, gerando renda e valorizando suas identidades. No Estado do Maranhão, movimentos como a Economia Solidária integram instituições empresariais, universidades e órgãos estatais para auxiliar grupos produtivos de diferentes regiões do estado, para compreender os potenciais locais como estratégias políticas e econômicas viáveis, iniciativas que, segundo Gaiger (2011), são um fenômeno observado em muitos países há pelo menos uma década, fundamentados nos princípios da autogestão, cooperação e solidariedade.

A Economia solidária também se consolida como uma reflexão sobre as desigualdades sociais existentes através dos problemas do capitalismo. Gaiger (2011) também aponta que as ações e princípios desta economia exigem o caráter emergencial de direito dos cidadãos (como políticas sociais) e a necessidade de novos pensamentos e soluções no sistema capitalista para se opor a princípios do mercado globalizado e da racionalidade da acumulação privada.

Em meio à necessidade de promover formas solidárias de economia social entre diversos setores que lutam por dignidade, sustentabilidade e reconhecimento, estes que segundo Cattani (2003) geralmente são mercados populares, grupos de produção comunitária, associações e cooperativas, estão projetos como o Maranhão Desenvolvido Mais Justo e Solidário, uma das ações do plano estratégico Mais IDH, gerenciado pelo governo do estado do Maranhão e executado pela Secretaria do Estado do Trabalho e Economia Solidária, para inserir e melhorar experiências e possibilidades para diversas comunidades situadas em municípios que apresentam, de maneira significativa, situações de vulnerabilidade social, a partir de planos para o fortalecimento e valorização de pequenos empreendimentos, potencializando as características, realidades e metas de cada uma dessas localidades.

Para contribuir com a formação de redes colaborativas, fomento de políticas públicas estaduais e estratégias de produção, divulgação e comercialização de produtos nas comunidades, a presença de agentes de acompanhamento e apoio através da Fundação Grupo Esquel e Centros de Referência de Economia Solidária como o CRESOL Maranhão se tornam importantes, no apoio técnico em autogestão e na formalização de empreendimentos e viabilizando espaços e meios de comercialização no estado e no país, tornando efetivo o acesso em eventos, feiras e centros de artesanato e produção familiar. Percebendo as múltiplas diferenças culturais de grupos que trabalham com artesanato, extração e transformação de materiais do ambiente local, assim como conhecimentos tácitos e históricos de produtores, artesãs e artesãos, se torna interessante para o movimento da Economia Solidária estudar tangibilizar identidades por meio do Design.

Este artigo pretende mostrar algumas práticas e ferramentas colaborativas em ação, realizadas nos contatos entre o Núcleo de Pesquisas em Inovação, Design e Antropologia (NIDA) ${ }^{1}$, da UFMA, com grupos produtivos do Maranhão no âmbito do Projeto Maranhão Desenvolvido Mais Justo e Solidário, visando alternativas viáveis para melhorar os pequenos empreendimentos entendendo como funcionam os processos produtivos, o uso de materiais e a criatividade de comunidades para gerar elementos gráficos, produtos e embalagens sustentáveis, em nove regiões do estado: Lençóis, Munim, Médio Mearim, Cerrado Amazônico, Baixo Parnaíba, Cocais ,Vale do Itapecuru, Lagos e Litoral Norte e a Região Metropolitana do Estado. É necessário compreender o papel do design nas dinâmicas sociais e culturais, ao longo da pesquisa, vão sendo entendidas as narrativas de vida, tecnologias locais e impasses dos grupos que são questões muito importantes nesta abordagem participativa.

\section{Codesign e comunicação dos territórios}

Entendendo o propósito do projeto de colaborar com a diversidade produtiva de comunidades em diversas regiões do estado de forma democrática e solidária por meio de tangibilizações dos aspectos culturais locais, é necessário refletir as relações entre design e território e princípios que permitam a participação de todos os envolvidos nas etapas projetuais, em um processo de codesign. Primeiro,

\footnotetext{
${ }^{1}$ O projeto de pesquisa Correspondências sobre o projetar e o fazer: codesign e construção de conhecimento entre designers e praticantes habilidosos, foi aprovado pelo Edital Universal 2018 da FAPEMA, recebendo a resolução CONSEPE $1880 \mathrm{em} 28$ de junho de 2019. Foi por meio deste projeto que se estabeleceu a pesquisa com o Governo do Estado do Maranhão, por meio da Fundação Esquel do Brasil e Fundação Sousândrade.
} 
reconhecendo o potencial da pesquisa-ação no contato direto com as comunidades, experiências definidas por Reason \& Bradbury (2001) como propostas de integração e contextualização nos ambientes de trabalho investigando seus aspectos sociais, políticos e econômicos, para estabelecer relações igualitárias e responsáveis entre os participantes.

Torna-se crucial reconhecer e estimular os grupos produtivos para a horizontalidade das formas de atuação e desenvolvimento de projetação onde todos aprendem e fazem juntos, pois como defende Manzini (2008), esses grupos já dispõem de diversos saberes e estratégias na busca de oportunidades e inovações, como comunidades criativas com capacidades e competências para resolver desafios de forma colaborativa. O designer então precisa trabalhar "sua sensibilidade, capacidades e habilidades para projetar novos artefatos que estimulem a colaboração entre membros das comunidades" (MANZINI, 2008, p. 83).

Estes artefatos apresentam-se ao longo deste processo como propostas e ferramentas de diálogo definidas pelas necessidades dos territórios, identidades visuais como possibilidade de comunicação que devem ser promovidas através de ações essenciais, definidas por Krucken (2009) como reconhecer (as qualidades do produto e do território), ativar (as competências do território), comunicar (o produto e o território), proteger (a identidade local, patrimônio material e imaterial), apoiar (a produção local), promover (sistemas de produção de consumos sustentável), desenvolver (produtos/serviços que respeitem a vocação e valorização do território) e consolidar (as redes do território). Krusser (2002) também discorre que a identidade visual é um vetor efetivo de transformação e visualização social, e isso é constatado à medida que o designer aprende e tangibiliza personalidades, culturas e propósitos junto a instituições e grupos, em atitudes participativas e de cocriação.

\section{Metodologia}

A pesquisa, subsidiada pelo Projeto Maranhão Desenvolvido Mais Justo e Solidário, foi realizada em três macro etapas, consistindo em planejamento, jornada nos territórios com os grupos e tangibilização de identidades, aconteceu entre janeiro e abril de 2020. Felizmente, a etapa de pesquisa de campo encerrou-se na primeira semana de março, antes da suspensão das atividades na Universidade, em função da COVID-19. A terceira etapa, aconteceu de forma virtual, inclusive a devolução dos resultados para os grupos produtivos.

Durante toda a condução da pesquisa, adotou-se como abordagem de base, as práticas de correspondências, propostas pelo antropólogo britânico Tim Ingold (2018). Por meio destas, foi possível pensar em maneiras de estabelecer trocas e criar vínculos com as pessoas, por meio do fazer junto, com os outros. Para o planejamento e realização das oficinas, utilizamos como base metodológica os princípios do codesign (MANZINI, 2015), para estabelecer espaços de criação democráticos e convidativos, no qual todos podem fazer parte da atividade de design, sendo eles profissionais com formação acadêmica na área ou pessoas que não possuem conhecimentos técnicos, mas conhecimentos tácitos, para resolver suas questões cotidianamente, os designers experts e designers difusos, respectivamente, como denomina o autor.

Para que cada marca tivesse um valor territorial identificável e tangível, acionamos as reflexões sobre as cadeias de valores propostas por Lia Krucken (2009) para a criação de ferramentas de identificação e análises dos dados qualitativos, posteriormente incorporados na elaboração do conceito das identidades visuais.

Para o desenvolvimento dessas ferramentas, também adotou-se os conceitos dos dispositivos de conversação (ANASTASSAKIS \& SZANIECKI, 2016) e dos jogos mediativos (NORONHA, 2015), questões primordiais para a criação de espaços democráticos, visando diálogos fluidos para tratar de questões sociais que não são explicitadas rotineiramente ou nem mesmo imaginadas, partindo do princípio de que, a partir da ludicidade, é possível pensar em questões não experienciadas integralmente utilizando da imaginação na proposição de futuros possíveis.

Além disso, utilizou-se o Benchmarking (LACOMBE; HEILBORN,2003) como ferramenta de apresentação de referências, para que partir do painel visual de marcas de segmentos semelhantes fosse possível a facilitação da conversa sobre a importância da identidade visual como maneira de representação dos grupos, apresentação da estrutura e das informação que compõe cada uma delas, 
como cores, elementos gráficos, tipografias, símbolos e ícones. Em síntese apresenta-se as etapas metodológicas adotadas:

Quadro 1 - Etapas metodológicas do projeto

\begin{tabular}{|c|c|c|}
\hline \multirow{2}{*}{ Planejamento } & $\mathbf{1}$ & Apresentação dos objetivos/grupos e territórios. \\
\cline { 2 - 4 } & $\mathbf{2}$ & Processo de seleção de grupos/territórios \\
\cline { 2 - 4 } & $\mathbf{3}$ & Mapeamento dos grupos/territórios \\
\cline { 2 - 4 } & $\mathbf{4}$ & Desenvolvimento de ferramentas para correspondência criativa \\
\hline \multirow{2}{*}{$\begin{array}{c}\text { Jornada nos } \\
\text { territórios }\end{array}$} & $\mathbf{5}$ & Oficinas (roteiro/grupos/deslocamento) \\
\hline \multirow{2}{*}{$\begin{array}{c}\text { Tangibilização de } \\
\text { identidades }\end{array}$} & $\mathbf{6}$ & $\begin{array}{c}\text { Sistematização e análise dos dados em campo (planejamento das } \\
\text { marcas) }\end{array}$ \\
\cline { 2 - 4 } & $\mathbf{7}$ & Desenvolvimento de marcas (diretrizes do projeto gráfico) \\
\cline { 2 - 4 } & $\mathbf{8}$ & Apresentações, escuta e diálogos sobre os resultados. \\
\hline
\end{tabular}

Quadro 1: Descrição resumida das etapas que nortearam o projeto. Fonte: Os autores.

\section{Planejamento e jornadas nos territórios}

O processo de planejamento tem início nos dias 13 e 14 de janeiro de 2020, ocorrendo, no primeiro dia na sede da SETRES - Secretaria do Trabalho e Economia Solidária, e, no segundo, no Centro de Ciências Exatas e Tecnologia da Universidade Federal do Maranhão, onde se situa o Núcleo de Pesquisa em Inovação, Design e Antropologia, objetivando apresentar as equipes NIDA-UFMA, da SETRES e da ESQUEL, estabelecer rodas de conversa para exposição dos objetivos projetuais que deveriam ser alcançados com a pesquisa, a apresentação dos territórios e cada grupo que já estavam sendo acompanhados pela instituição mediadora e, em contraponto, a apresentação de trabalhos anteriores realizados pelo núcleo de pesquisa e os resultados de suas experiências. A reunião contou com a presença de duas coordenadoras da SETRES, que apresentaram os pontos chave do projeto Maranhão desenvolvido mais justo e solidário, além da coordenadora do NIDA e mais sete pesquisadores do núcleo de pesquisas, e também de oito agentes da ESQUEL, responsáveis pelo acompanhamento das regiões dos grupos indicados.

Desta forma foi possível considerar os primeiros aspectos relacionados à identidade cultural, econômica e social a serem aprofundados, como as articulações com cooperativas, conflitos de terra, saberes tradicionais passados por gerações e o anseio em comum de contribuir com o meio ambiente e gerar renda em grupos em situação de desarticulação ou venerabilidade econômica por meio da melhoria dos processos produtivos, divulgação e comercialização de produtos que carregam histórias e lutas, frente a um sistema capitalista que dificulta os propósitos dos grupos. Trabalhar o Design nesse contexto assim como relacioná-lo com a Economia Solidária é um desafio complexo, pois como reforça Singer (2002),

A construção de um modo de produção alternativo ao capitalismo no Brasil ainda está no começo, mas passos cruciais já foram dados, etapas vitais foram vencidas. Suas dimensões ainda são modestas diante do tamanho do país e de sua população. Mesmo 
assim, não há como olvidar que dezenas de milhares de pessoas já se libertaram pela solidariedade. $\mathrm{O}$ resgate da dignidade humana, do respeito próprio e da cidadania dessas mulheres e destes homens já justifica todo esforço investido na Economia Solidária. É por isso que ela desperta entusiasmo (SINGER, 2002a, p.127).

Posteriormente, fez-se a seleção de grupos em conjunto, a partir de princípios estabelecidos como: diversidade nos tipos de grupos produtivos, adesão ao processo, acessibilidade, status da fase de comercialização, contrapartida, identidade coletiva enquanto grupo, requisitos e planos relacionados à sustentabilidade. Além disso, realizou-se a organização e mapeamento dos territórios para o planejamento de visitas, visando a realização de oficinas criativas com as pessoas de cada um dos grupos selecionados pelo projeto.
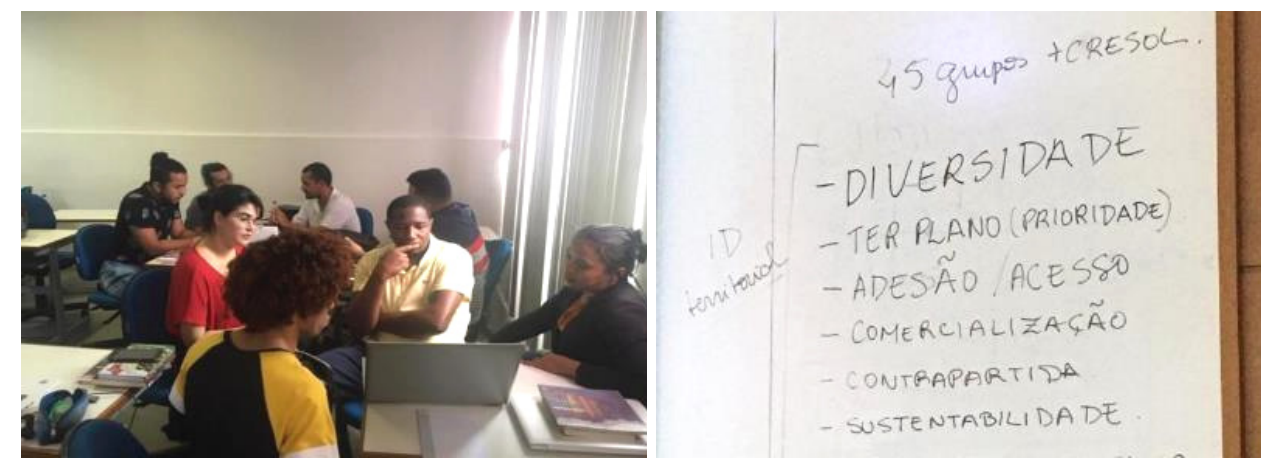

Imagens 1 e 2: Grupos de trabalho para definição dos grupos produtivos e princípios definidos para a inclusão dos empreendimentos. Fonte: Os autores.

Levando em consideração este desafio e o papel do Design em responsabilidade social, se faz importante o acompanhamento local e detalhado para conhecer os territórios, dialogar com os grupos e entender a complexidade dos processos produtivos, pois os dados apresentados pelos agentes que representavam as regiões demonstravam que cada grupo possuía tipos de materiais e produtos diversos. Alguns grupos trabalham com a produção e a venda de artesanato, outros a de alimentos, e também necessidades por projetos de espaço, entre outros. Na maioria dos casos apresentados haviam fortes ligações do trabalho à fé (grupos ligados às igrejas), à ancestralidade e políticas sociais (grupos indígenas, MST e afro descendentes).
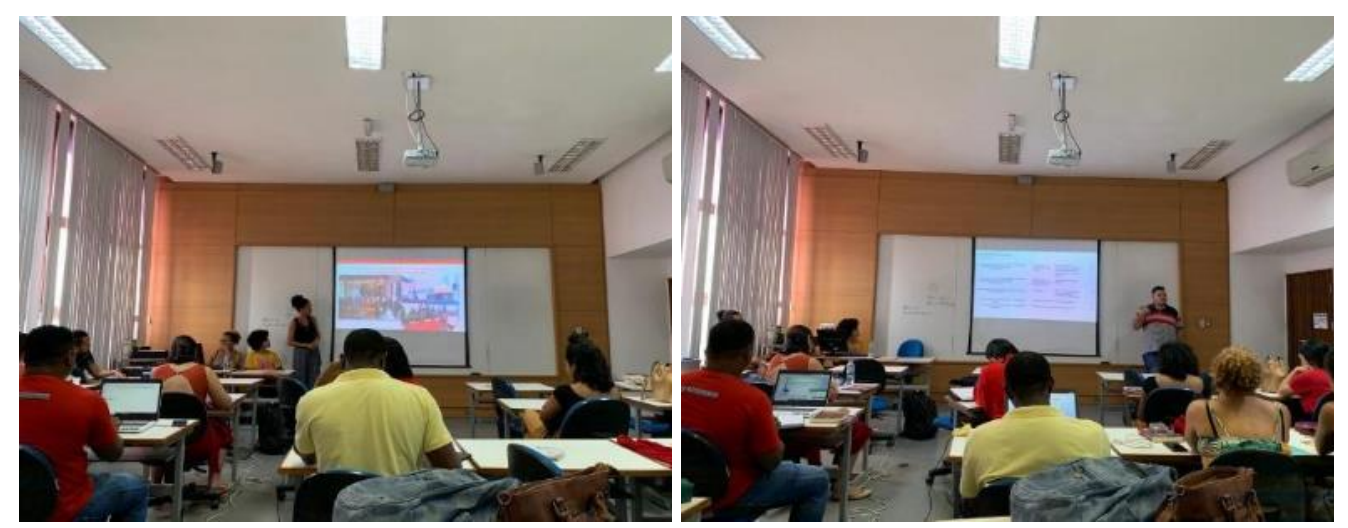

Imagens 3 e 4: Apresentação dos grupos e territórios pelos agentes da Esquel. Rodas de conversa e discussões a respeito da seleção dos grupos. Fonte: Os autores.

A partir disso, foi possível estabelecer uma jornada aos territórios, lançando mão de conhecimentos do campo da antropologia para contemplar as ações e ferramentas de cunho qualitativo, pois segundo Gunn et al. (2013, p.2) ela se caracteriza como um o estudo comparativo de sociedades e culturas, baseado em pesquisas empíricas detalhadas em contextos sociais concretos. Unindo ao design, as reflexões debatidas no âmbito de Design Anthropology como linha de 
pensamento, pesquisa e forma de atuação, busca propor maneiras para facilitar a participação ativa de todos os atores sociais envolvido no projeto, de maneira prática, de forma a agir, como sugere Tunstall (2013), como prática descolonizada de engajamento cultural, reconhecendo e reforçando a territorialidade e diversidade de contextos. Após os debates das reuniões de planejamento, chegamos a esta lista de 41 grupos, dos quase 150 atendidos até então nas etapas anteriores do projeto:

Quadro 2 - Territórios e descrições de grupos produtivos no projeto

\begin{tabular}{|c|c|c|c|}
\hline TERRITÓRIO & $\mathbf{N}^{\circ}$ & GRUPOS & MUNICÍPIO \\
\hline \multirow{2}{*}{$\begin{array}{c}\text { REGIÃO } \\
\text { METROPOLITANA }\end{array}$} & 1 & Amigas Solidárias & São Luís \\
\hline & 2 & Madesol & Paço do Lumiar \\
\hline \multirow{3}{*}{$\begin{array}{l}\text { LAGOS E } \\
\text { LITORAL NORTE }\end{array}$} & 3 & Terreiro Os Filhos e Filhas de Ogum & Cururupu \\
\hline & 4 & Bumba Meu Boi de Boa Vista & Cururupu \\
\hline & 5 & Aldeia Nova Vila de Taquaritiua & $\begin{array}{l}\text { Viana - Aldeia Nova Vila de } \\
\text { Taquaritiua }\end{array}$ \\
\hline \multirow{5}{*}{ MUNIM } & 6 & $\begin{array}{l}\text { Cooperativa Agroecológica de Agricultores e } \\
\text { Agricultoras Familiares da Economia Solidária de } \\
\text { Rosário }\end{array}$ & Rosário \\
\hline & 7 & Associação de Mulheres Semeando a Resistência & Rosário \\
\hline & 8 & Mulheres Unidas pelo Bem Viver & Rosário \\
\hline & 9 & Novo Olhar & Bacabeira \\
\hline & 10 & Centro de Artesanato de Presidente Juscelino & Presidente Juscelino \\
\hline \multirow{5}{*}{ BAIXO PARNAÍBA } & 11 & Artesãs em Ação & Água Doce do Maranhão \\
\hline & 12 & São João dos Pilões & Brejo \\
\hline & 13 & Tecendo Sonhos & Brejo \\
\hline & 14 & Resex Chapada Limpa & Chapadinha \\
\hline & 15 & Mulheres Empreendedoras & Água Doce do Maranhão \\
\hline \multirow{8}{*}{$\begin{array}{l}\text { CERRADO } \\
\text { AMAZÔNICO }\end{array}$} & 16 & Mãos que cuidam & Imperatriz \\
\hline & 17 & Casa do MST & Imperatriz \\
\hline & 18 & Sabor da Conquista & Açailândia \\
\hline & 19 & Da Horta pra Cozinha & Açailândia \\
\hline & 20 & Mulheres Artesãs de Pequiá de Baixo & Açailândia \\
\hline & 21 & Mulheres da Água Preta & Amarante do Maranhão \\
\hline & 22 & Fêminna & Imperatriz \\
\hline & 23 & Assentamento Califórnia - Verde é Vida & Açailândia \\
\hline \multirow{5}{*}{ LENÇÓIS } & 24 & Artecoop & Barreirinhas \\
\hline & 25 & $\begin{array}{l}\text { Associação de Moradores e Pescadores do Bar } \\
\text { da Hora }\end{array}$ & Barreirinhas \\
\hline & 26 & Associação das Artesãs de Boa Vista & Barreirinhas \\
\hline & 27 & Arte e Produção & Paulino Neves \\
\hline & 28 & COOPPAFAM Primeira Cruz & Primeira Cruz \\
\hline
\end{tabular}


Quadro 2 - Territórios e descrições de grupos produtivos no projeto (continuação)

\begin{tabular}{|c|c|c|c|}
\hline \multirow{9}{*}{ MÉDIO MEARIM } & 29 & Bolo \& Cia. & Bacabal \\
\hline & 30 & Casa das Polpas & Bacabal \\
\hline & 31 & Farinha Pé da Serra & Esperantinópolis \\
\hline & 32 & Grupo Esperança - Polpa de Fruta Bom Gosto & Trizidela do Vale \\
\hline & 33 & Produtos Barroso & Esperantinópolis \\
\hline & 34 & Mulheres Empreendedoras do Artesanato & Esperantinópolis \\
\hline & 35 & $\begin{array}{c}\text { AMALC - Associação das Mulheres Artesãs de } \\
\text { Lima Campos }\end{array}$ & Trizidela do Vale \\
\hline & 36 & Mulheres de Fé - Extrativismo do Coco Babaçu & Trizidela do Vale \\
\hline & 37 & Mulheres Guerreiras & Trizidela do Vale \\
\hline \multirow{4}{*}{$\begin{array}{l}\text { COCAIS E VALE DO } \\
\text { ITAPECURU }\end{array}$} & 38 & $\begin{array}{c}\text { ABARC - Associação Beleza das Artes da Região } \\
\text { dos Cocais }\end{array}$ & Timon \\
\hline & 39 & Grupo de Mulheres Mãos Criativas & Timon \\
\hline & 40 & Biscoito Santa Fé & $\begin{array}{l}\text { Matões do Norte - Povoado } \\
\text { Assentamento Sozinho }\end{array}$ \\
\hline & 41 & Sorvete Raízes & $\begin{array}{c}\text { Itapecuru Mirim - Povoado } \\
\text { Quilombo Monge Belo }\end{array}$ \\
\hline
\end{tabular}

Quadro 2: Informações sobre localização e identificação de comunidades e grupos produtivos indicados. Fonte: Os autores.

Estas jornadas nos territórios aconteceram seguindo dois momentos em cada grupo produtivo visitado; no primeiro realizando um diálogo sobre a relação com as matérias-primas locais, as relações de beneficiamento através de instituições e parceiros, as etapas produtivas para a geração dos produtos, assim como as formas de distribuição, comercialização, encomendas e entrega realizadas; e no segundo momento, apresentando o benchmarking desenvolvido como ferramenta de estímulo à conversa, para sanar dúvidas e questionamentos e, em seguida, realizando desenhos coletivos. A apresentação de equipamentos, embalagens e de todos os materiais envolvidos no trabalho das comunidades também foi importante para a efetividade das ferramentas e alternativas trabalhadas.

\section{Compreendendo e representando identidades: Criatividade e Ferramentas}

A interação e trabalho conjunto no projeto com as comunidades podem ser visualizados como um processo de codesign, no qual a comunicação e referências tangíveis contribuem em identidades e tangibilizações responsáveis e convenientes às expectativas e repertório dos grupos produtivos.

A oportunidade de cocriarão através de oficinas, propondo a utilização de ferramentas como o Benchmarking (LACOMBE; HEILBORN, 2003) e a Estrela de Valor, a partir das categorias propostas por Krucken (2009), para estimular a criatividade e compartilhamento de informações sobre a visão de grupos produtivos em relação ao seu trabalho e princípios, permitiu com que os envolvidos ficassem mais confortáveis em relação à mudanças e novas perspectivas para repensar embalagens, identidades visuais (existentes ou não) e a forma de fazer produtos, inspirando e gerando novas imagens, artefatos e ideias. 


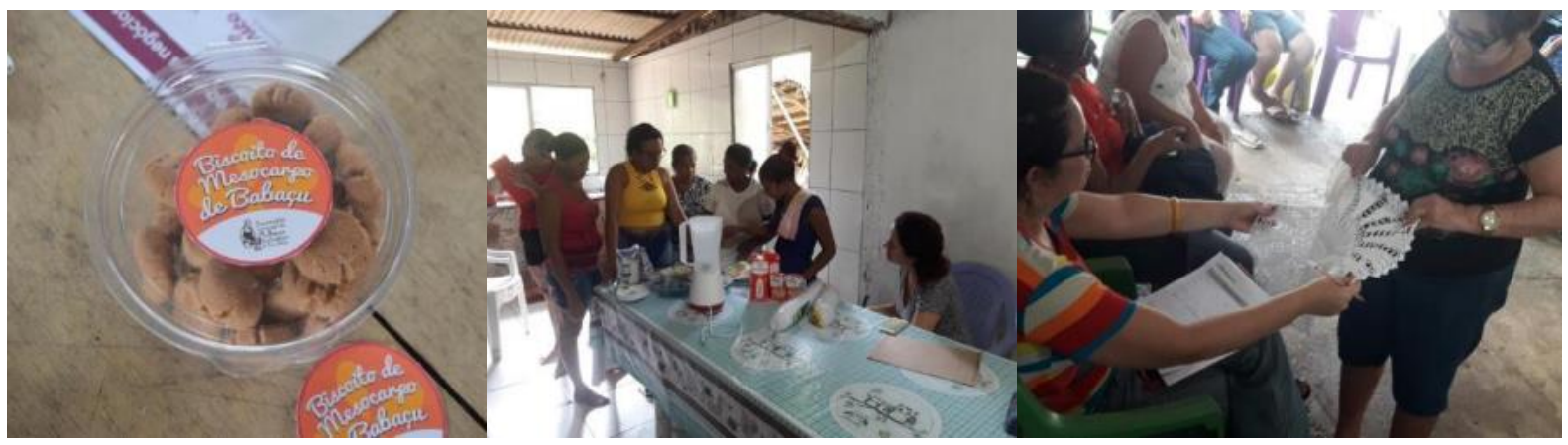

Imagens 5, 6 e 7: Momentos de acompanhamento das práticas produtivas e observação de recursos físicos e gráficos disponíveis nas comunidades de Aldeia Nova Vila de Taquaritiua (Viana), Quilombo Monge Belo

(Itapecuru Mirim) e Timon, no Maranhão. Fonte: Os autores.

Durante as visitas foi possível observar tanto as referências simbólicas e estéticas, como também o uso dos materiais, sintéticos ou naturais, na prática (Ver imagem 6.). Desta forma tornou-se evidente que os grupos poderiam utilizar inspirações locais, processos de atribuição de valor e aproveitamento da rica cultura, a partir dos seus próprios territórios, na transformação dos produtos, verificando a importância de representar os valores agregados e transmitir informações que pudessem ser facilmente entendidas e apreciadas tanto pelos grupos quanto pelos consumidores/clientes dos produtos.

\subsection{Diálogos sobre as cadeias produtivas e Estrela de Valor}

O traçado e análise da estrela de valor e o mapeamento preliminar das cadeias produtivas foram as atividades deste momento. Isto acontece para que os dados e as informações coletadas sejam tratados, gerando conhecimento que será tangibilizado através de imagens. Desta forma os problemas e soluções identificados serão representados nas ferramentas, podendo também gerar cruzamentos entre cada comunidade produtora, a partir do desenho de cada cadeia produtiva, buscando também uma síntese regional, por território.

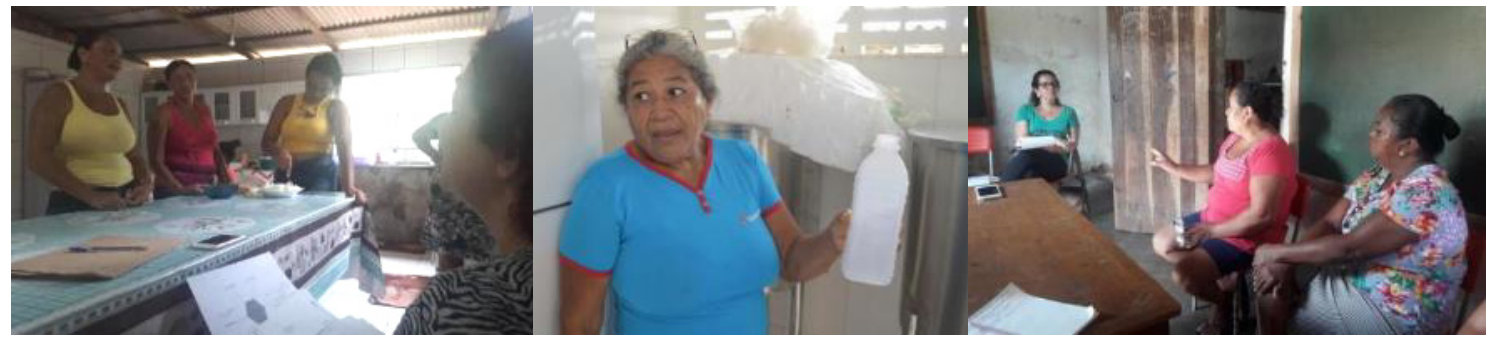

Imagens 8, 9 e 10: Acompanhamento de etapas de cadeias produtivas, diálogos e aplicação da Estrela de Valor nas comunidades de Quilombo Monge Belo (Itapecuru Mirim), Aldeia Nova Vila de Taquaritiua (Viana) e Assentamento Povoado Sozinho (Matões do Norte), no Maranhão. Fonte: Os autores

Os diálogos sobre as cadeias produtivas foram feitos tanto através de rodas de conversa quanto acompanhando de perto, quando possível, todas as etapas de aquisição e preparo de materiais para a construção de produtos, como a produção de azeite de Coco Babaçu pela aldeia Nova Vila de Taquaritiua onde acompanhou-se desde a coleta de coco até as considerações sobre o armazenamento (Ver imagem 9.). A Estrela de valor foi uma ferramenta preenchida durante os diálogos e por meio desta, foi possível compreender e categorizar alguns aspectos sobre a qualidade dos produtos, os significados e emoções das comunidades em relação à produção e relações de trabalho, além de outros tópicos a serem analisados com responsabilidade e sensibilidade. 


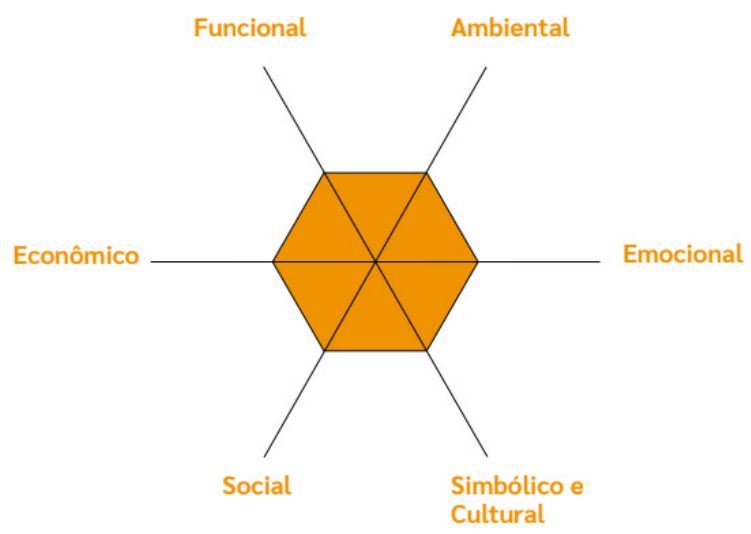

Imagem 11: Representação gráfica da Estrela de Valor. Fonte: Krucken (2009).

A estrela possui seis dimensões de valor em relação ao produto e à própria cadeia produtiva ou organização das comunidades, definidas por Krucken (2009) como: o funcional ou utilitário, que se caracteriza pela "adequação ao uso", referindo-se às qualidades intrínsecas do produto, sua composição, origem e propriedades, à segurança de consumo e a aspectos ergonômicos; $\mathrm{O}$ valor emocional, que incorpora motivações afetivas relacionadas às percepções sensoriais que compreendem componentes táteis, visíveis, olfativos e gustativos e o sentimento relacionado à compra e ao consumo/utilização do produto, além de incorporar, ainda, a nossa dimensão "memorial", relativa a lembranças positivas e negativas de acontecimentos passados; $\mathrm{O}$ valor ambiental, vinculado principalmente à prestação de serviços ambientais por meio do uso sustentável dos recursos naturais como as florestas; $\mathrm{O}$ valor simbólico e cultural, relacionado à importância dos saberes e produtos nos sistemas de produção e de consumo, nas tradições e nos significados espirituais, da origem histórica e do sentido de pertencimento associado ao desejo de manifestar a identidade social, pertencimento em grupo étnico, posicionamento político, dentre outras intenções; $\mathrm{O}$ valor social, que se relaciona aos aspectos sociais que permeiam os processos de produção, comercialização e consumo dos produtos; E o valor econômico, de caráter objetivo, que se baseia na relação custo-benefício em termos monetários.

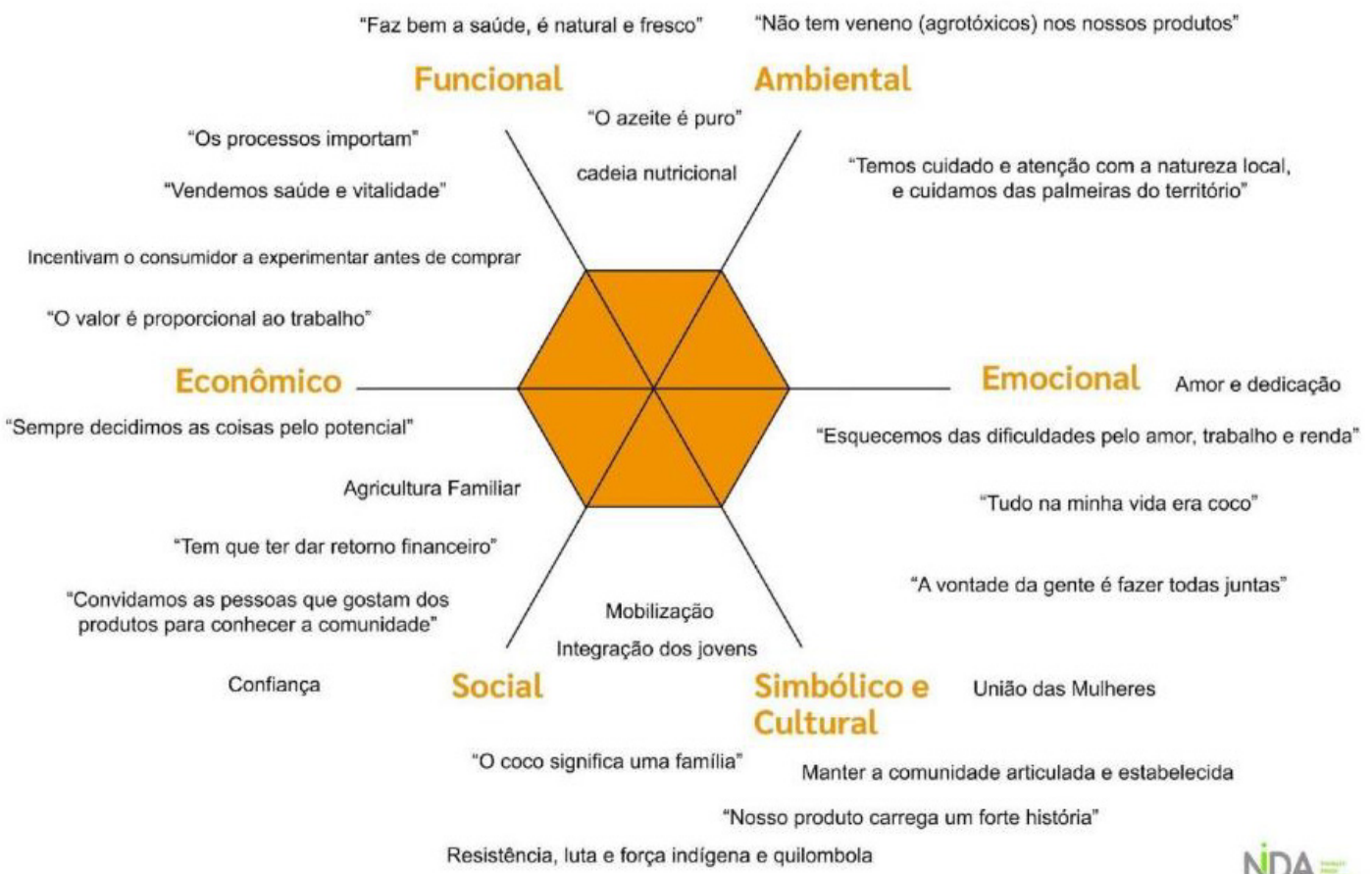

Imagem 12: Exemplo de aplicação da estrela de valor segundo diálogos com produtores da Aldeia Nova Vila de Taquaritiua (Viana), no Maranhão. Fonte: Os autores, adaptado de Krucken (2009). 
Todos esses valores distribuídos (ver imagem 12.) podem ser utilizados para potencializar outras ferramentas de criatividade e aproximação aos grupos produtivos, além de servirem de direcionamento para representações gráficas e informativas sobre os processos produtivos. Assim entendemos grande parte do sistema, motivações e dificuldades que envolvem um contexto, dados que são refletidos não só na produção, mas nos próprios produtos. Muitos valores precisam ser preservados por questões históricas e culturais, e outros precisam ser estudados ou repensados para o alcance dos objetivos das comunidades.

\subsection{Benchmarking e a Criatividade em desenhos coletivos}

No segundo momento das visitas aos grupos produtivos, fez-se a apresentação do benchmarking, uma ferramenta muito interessante para apresentação de marcas similares, nacionais ou locais, que podem ser identificadas pelos envolvidos no projeto ou servir de inspiração para o desenho coletivo. "Benchmarking é um processo contínuo de medição de produtos, serviços e práticas em relação aos mais fortes concorrentes, ou às empresas reconhecidas como líderes" (LACOMBE; HEILBORN, 2003, p. 470).

Levando em consideração as diferenças de cadeias produtivas e produtos nas regiões do Maranhão e os empreendimentos existentes no trabalho, dividimos as marcas em 4 categorias: Empreendimentos sociais (serviços), agricultura, artesanato e trabalhos manuais e pequenos negócios. Esta ferramenta contribui para que os produtores entendam a importância de identidades visuais na divulgação e comercialização de produtos e prospectando individualmente seus interesses para representá-los no papel, como mais um potencializador de criatividade em exemplos de formas, cores e informações. A partir da visualização é possível dialogar antes do momento do desenho para entender propósitos e dúvidas, e até mesmo proporcionando o entendimento do que é uma marca, já que em alguns grupos este conceito era desconhecido pelos integrantes.

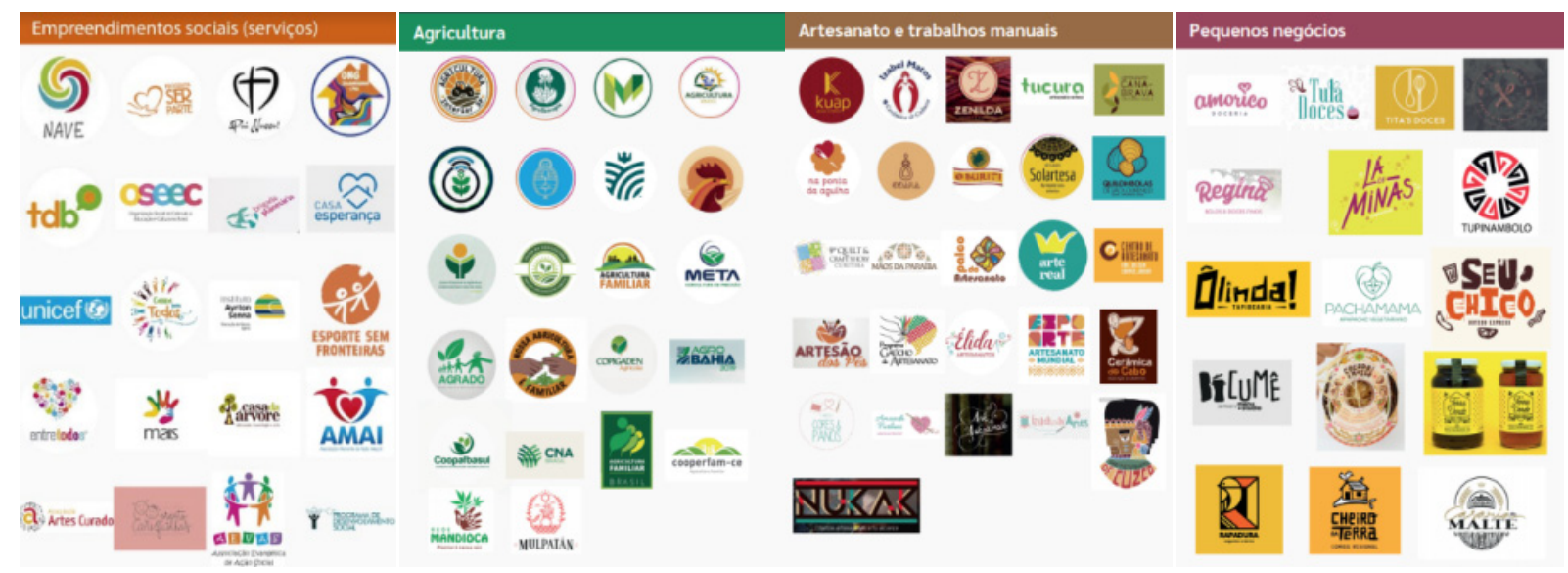

Imagens 13, 14, 15 e 16: Benchmarking direcionado às marcas nacionais com processos produtivos ou produtos semelhantes aos das comunidades envolvidas no projeto. Fonte: Os autores.

Todas as opiniões sobre essa ferramenta são importantes e devem ser consideradas na construção de alternativas, estas marcas devem ser casos reais e já aplicados para a identificação das melhores práticas e a projeção de performances futuras de produção. Após o momento de conversa sobre o benchmarking, optamos por recolher a ficha do benchmarking, próximo do momento do desenho, para evitar semelhanças nas representações.

Após as observações sobre o benchmarking, há o momento coletivo de desenho de marca ou inspirações, no qual convidamos a todos os integrantes dos grupos produtivos a compartilhar suas visões e expectativas pessoais sobre suas vivências e produções (Ver imagens 17 e 19). 


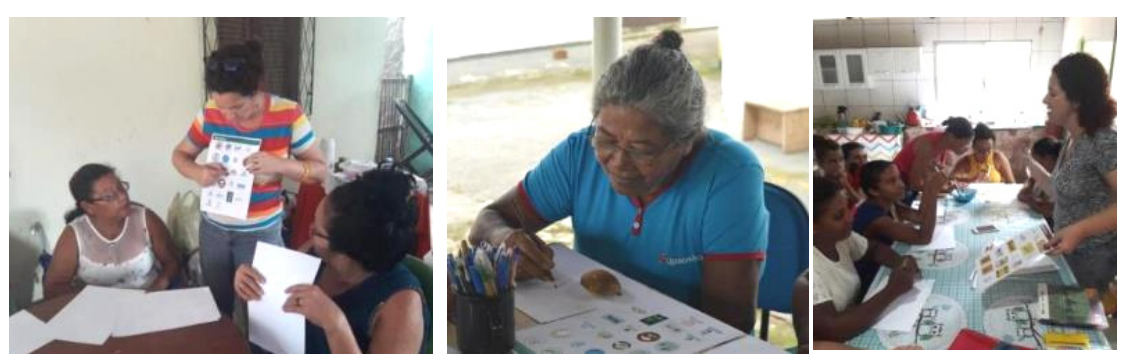

Imagens 17, 18 e 19: Discussões sobre o benchmarking selecionado segundo a categoria de cadeia produtiva. Fonte: Os autores.

Desta forma transformamos os diálogos e repertórios coletivamente em formas, símbolos e cores, valorizando e estimulando as capacidades artísticas de cada um em cocriação, em mais um momento de aproximação, onde todos fazem juntos e sentem-se incluídos e essenciais no processo. Isso reforça o que Gatt e Ingold (2013) propõem como a relação intrínseca entre saber e fazer em correspondência, com propostas de desenho alternativas e usos criativos de materiais do território propostos por comunidades, como a inclusão de matérias-primas e produtos na roda de desenho para molde e inspiração de imaginário (Ver imagem 18.), pois como também defende Escobar (2016) membros de comunidade em práticas colaborativas possuem autonomia para praticar o design de si mesmos.

Utilizar o benchmarking e promover o desenho coletivo aproximando todos do grupo para representar a marca com elementos e imagens que sejam importantes para a comunidade em relação à história, cultura e motivações locais se mostrou um momento bastante integrador e divertido no qual o codesign mais uma vez se evidencia, pois todos os presentes se sentem parte da construção de melhores possibilidades e da própria identidade a ser adaptada ou desenhada. Não é necessário "saber desenhar", mas reconhecer a importância de qualquer representação sobre a realidade que é vivida por essas pessoas. Desta forma, as informações e desenhos irão gerar as identidades visuais e aplicações.

\section{Resultados}

Através do processo colaborativo com as comunidades, conhecendo presencialmente os grupos produtivos, dialogando sobre os diversos aspectos econômicos, sociais e culturais que fazem parte de cada território e utilizando as ferramentas de contextualização, criatividade e representação foi possível entender todos os aspectos identitários e expectativas tanto de grupos com produção única quanto semelhantes, construindo as identidades visuais segundo a linguagem e interesses apresentados nas experiências segundo os valores e características regionais e de cada grupo. Para uma melhor visualização e compreensão do alcance da pesquisa e da dimensão e diversidade territorial do projeto, assim como seus tipos de atividades organizamos um mapa de localização da ação (Ver Imagem 20.) e um gráfico de identificação produtiva (Ver gráfico 1.), recursos gráficos a seguir:
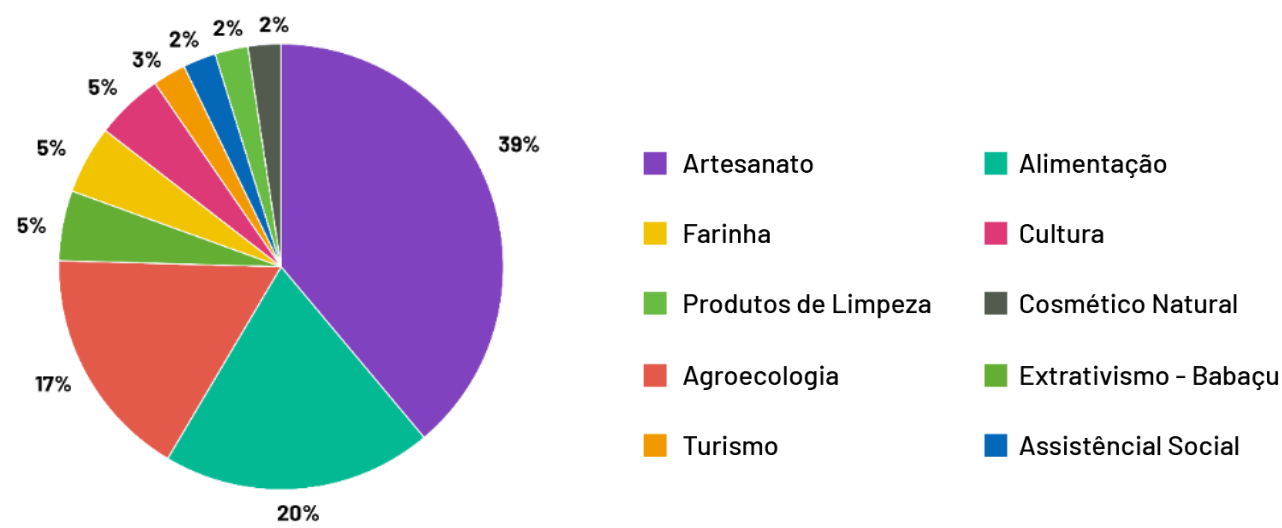

Gráfico 1 - Categorias produtivas dos grupos de economia solidária. Fonte: Os autores. 


\section{- Grupos Produtivos}

\section{Mapeamento}
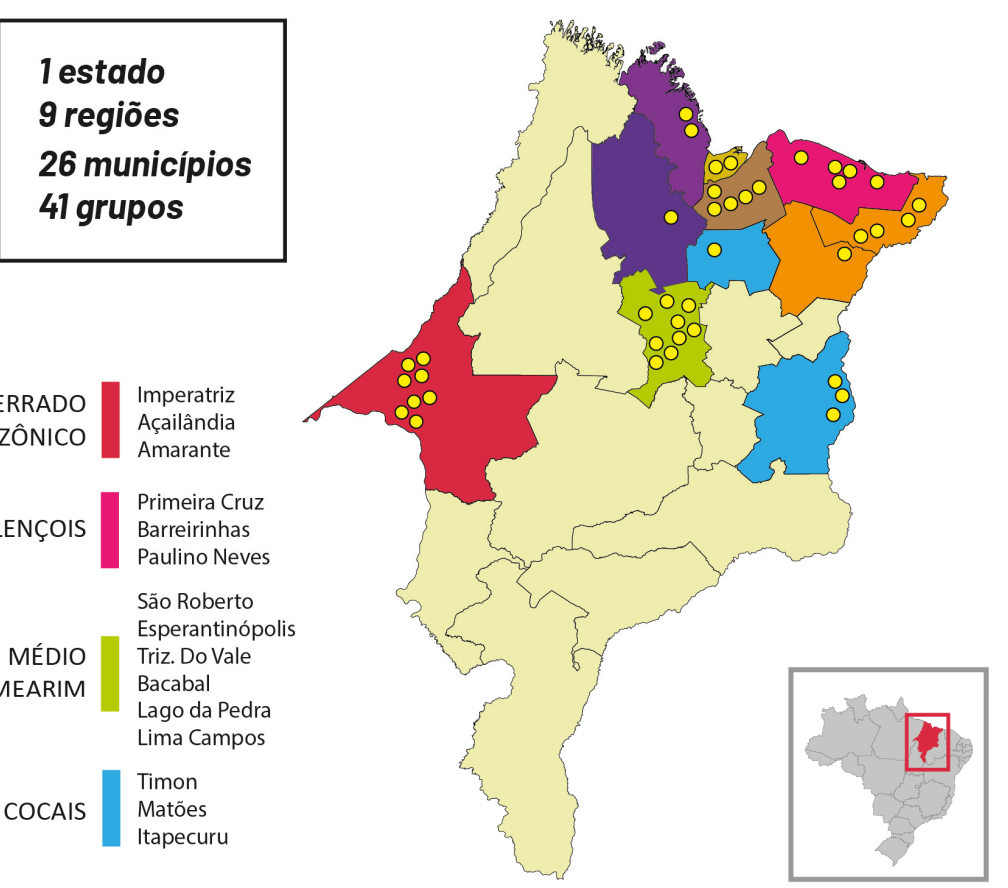

Imagem 20: Mapa de localização de ação do projeto, com as classificações territoriais segundo o interesse e características das regiões. Fonte: Os autores.

O compartilhamento dos resultados se deu com a apresentação dos projetos a toda a equipe gestora, aos representantes dos grupos e agentes, para a realização de ajustes necessários visando dirimir dúvidas e adequar a produção coletiva de imagens e produtos elaborados em cocriação (como marcas, identidades visuais de espaços de comercialização e embalagens).
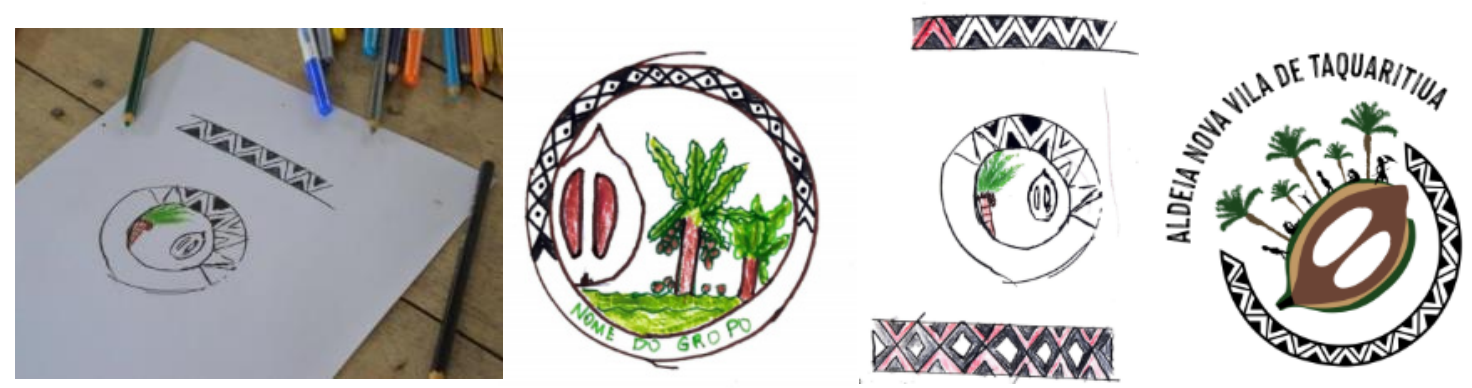

Imagens 21, 22, 23 e 24: Transformação das representações por meio das oficinas em identidades visuais, estas sendo referentes à Aldeia Nova Vila de Taquaritiua (Viana), no Maranhão. Fonte: Os autores.
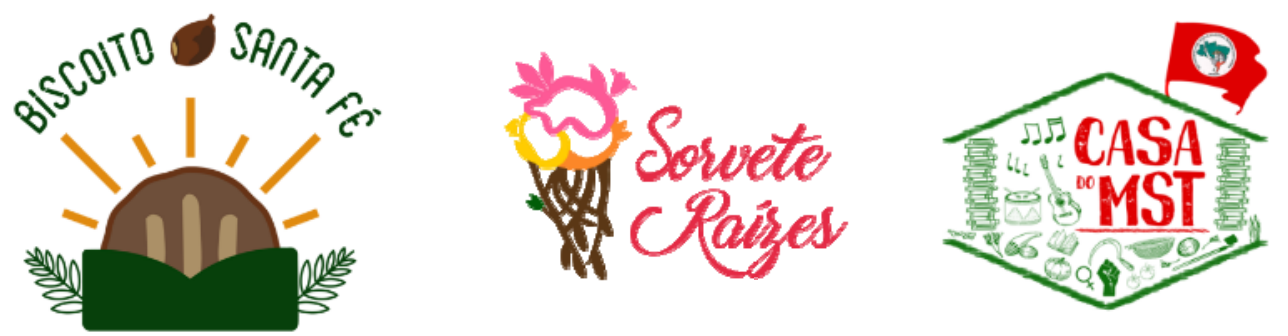

Imagens 25, 26 e 27: Outros resultados de identidades produzidas com o grupo produtivo Biscoito Santa Fé (Assentamento Povoado Sozinho em Matões do Norte), Sorvete Raízes (Quilombo Monge Belo em Itapecuru Mirim) e Casa do MST (Imperatriz), no Maranhão. Fonte: Os autores. 
Este compartilhamento das considerações e experiências de todo o processo com a apresentação de peças gráficas gera diversas considerações que devem ser adquiridas para fazer alterações necessárias e obter o feedback sobre a representatividade e potencial transformador do projeto colaborativo. A partir dos diversos relatos e a síntese de aprovações e ajustes (Ver gráfico 2.), percebe-se a ação contribuição positiva e a eficácia das abordagens e ferramentas utilizadas durante o processo.

"Eu só tenho a te agradecer, amei! Ficou lindo, tá lindo viu? Tá muito bonito mesmo, eu tô gostando muito! Tá muito maravilhoso! trabalho perfeito! Tá? amei, amei!" (Irene - Artesãs de Boa Vista - Boa Vista, Barreirinhas - MA)

"Em nome de todo grupo eu quero agradecer você e todo o grupo que trabalhou, e esforçando, o NIDA, fazendo o possível e o impossível pra conseguir chegar a esse ponto, nesse desenho maravilhoso que vocês fizeram, com essa marca, com esse foco que vocês tiveram com o que a gente fez, com o que a gente falou, com o que a gente desenhou..." (Kelly - Art\&Vida - Piranhas, Cana Brava -MA)

"Brigada! A gente lembra sim, porque como esquecer né? Foi um dia tão especial, maravilhoso, né? Vocês foram muito atenciosos com a gente. A gente tá muito feliz com o resultado do trabalho, eu pelo menos, estou muito feliz com pelo resultado, e tenho certeza que as outras também estão".

(Dorilene - ABARC, São Marcos, Timon-MA)

"Ficou muito bonito a marca. O interessante que eu achei é que porque juntou a ideia de todas, e formou e assim ficou do agrado de todas né? achei muito bonito, Lindo!" (Andreia - Sabor da Conquista, Açailândia-MA)

“... Foi mostrado a todas essas pessoas, ficaram admirados, gostaram, aplaudiram né? E ficou muito bom o seu trabalho, aliás, o nosso. Que agora é nosso né? Rs. Mas muito bom, graças a Deus. E nós gostamos viu? Nós só temos que agradecer." (Dona Expedita - Água Preta, Imperatriz - MA)

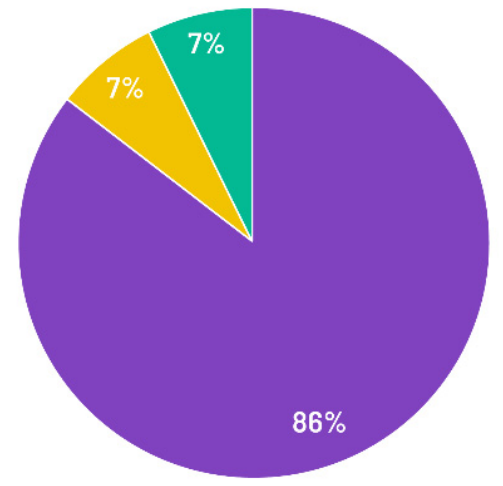

Aceitação sem ajustes

Aceitação com ajustes profundos

Aceitação com ajustes leves

Não aceitação

Gráfico 2 - Aprovações e pedidos de alterações do projeto, segundo opiniões das comunidades após receberem as identidades e peças. Fonte: Os autores.

A construção de meios digitais de informação e divulgação dos grupos produtivos também trouxe novas oportunidades às comunidades, com o acompanhamento dos agentes. Também levando em consideração o contexto pandêmico onde as comunidades tiveram que se afastar de muitos locais de comércio, dificultando a geração de renda de pessoas que sobrevivem do artesanato e de produtos 
territoriais, surgiu a ReSolVi ${ }^{2}$, plataforma digital de divulgação e venda onde as identidades podem ser utilizadas em uma rede solidária de comércio virtual. Desta forma os grupos podem facilitar o contato com clientes e turistas assim como abrir possibilidades de encomenda e valorização dos seus saberes.

\section{Considerações Finais}

O Projeto Maranhão Desenvolvido Mais Justo e Solidário mostrou-se como uma iniciativa de apoio a comunidades que muitas vezes não dispõem de acesso à informação e assistência, grupos que mesmo possuindo grandes potenciais de representação nacional, teriam muita dificuldade na conquista de espaços e oportunidades sem a Economia Solidária, que se apresenta como uma mudança significativa em meio às desigualdades econômicas e sociais.

Durante os diálogos com produtores, artesãos e artesãs percebeu-se o imenso potencial criativo e cultural do imaginário destas pessoas, e dos produtos, que precisam ser reconhecidos e difundidos, pois também constituem a história de um povo. É preciso transformar os grandes esforços dessas comunidades em benefícios que melhorem políticas públicas e assegurem direitos. $\mathrm{O}$ uso de jogos mediativos e dispositivos de conversação são fundamentais para o processo de tangibilização deste imaginário e dar-lhes existência material. O pouco tempo de contato com cada grupo foi potencializado pela ludicidade das práticas, que proporcionaram um rápido aprofundamento e mapeamento dos anseios dos grupos.

Relacionar design, economia solidária e antropologia para contribuir e trabalhar junto às comunidades e seus saberes tradicionais é um desafio que necessita de muita sensibilidade, cooperação e compreensão em relação à todas as diferenças e riquezas identitárias, entendendo que é preciso promover a participação de todos os envolvidos principalmente nas decisões mais cruciais do projeto. $\mathrm{O}$ design pode construir caminhos sustentáveis e solidários na sociedade quando prioriza o respeito e valorização dos saberes tradicionais e tácitos estimulando a criatividade na vivência territorial.

Outro resultado que merece destaque é o arranjo universidade pública e governo, quando observamos uma iniciativa que privilegia uma pesquisa-ação e o envolvimento de estudantes de graduação e mestrado, docentes, sociedade civil e o governo, trazendo um ampliação de horizontes para a sustentabilidade de ações integradas, cumprindo a prerrogativa de democratização do conhecimento produzido na universidade e sendo devolvido para sociedade.

\section{Codesign and solidarity economy: making identities tangible with productive groups from Maranhão}

Abstract: This article presents the process of contextualization, creativity and collaboration between the Center for Research in Design and Anthropology (NIDA-UFMA), Esquel Brasil Foundation and the Secretariat of Labor and Solidarity Economy (SETRES) with productive groups in Maranhão (41 groups and The Reference Center for Solidarity Economy - CRESOL). The work was carried out through the Maranhão Desenvolvido Mais Justo e Solidário project (promoted by the Maranhão State Government), with the objective of strengthening and articulating small enterprises with an economicsolidarity bias. Through visits and presencial interactions between those involved using tools such as the star of value, benchmarking and collective drawings, the experience brings reflections on the tangibilization of cultural identities in visual identities, the recognition of traditional knowledge as a projectual way for design, as well as considerations about codesign and solidarity economy, promoting quality of life, sustainability and opportunities to territories that use different materials and knowledge.

Keywords: Codesign; Solidarity economy; Creativity; Maranhão.

\footnotetext{
${ }^{2}$ Rede Solidária de Comercio Virtual que visa estimular o desenvolvimento de uma cultura do comércio e do consumo justo, responsável e solidário. Acesso disponível em: www.resolvi.ma.gov.br/municipio
} 


\section{Referências bibliográficas}

ANASTASSAKIS, Zoy; SZANIECKI, Barbara. Conversation Dispositifs: Towards a Transdisciplinary Design Anthropological Approach, in: Design Anthropological Futures. London: Bloomsbury, 2016.

CATTANI, D. A. (Org.). A Outra Economia. Porto alegre: Veraz, 2003.

ESCOBAR, Arturo. Autonomia y Diseño: La realizacion de lo communal. UC Editorial. Popaýan: Universidad del Cauca Colombia, 2016.

GAIGER, L. I. A dimensão empreendedora da economia solidária: notas para um debate necessário. São Leopoldo: Outra economia, Unisinos, v. 2, 2011.

GATT, Caroline; INGOLD, Tim; From Description to correspondence: Anthropology in real time. In: GUNN, Wendy; OTTO, Ton; SMITH, Rachel Charlotte (eds). Design Anthropology: theory and practice. London, New York: Bloomsbury, 2013.

GUNN, Wendy; OTTO, Tom; SMITH, R. C. Design Anthropology: Theory and Practice. London: Bloomsbury, 2013.

INGOLD, Tim. Anthropology and/as education. London: Routledge, 2018.

KRUCKEN, L. Design e território: valorização de identidades e produtos locais. São Paulo: Studio Nobel, 2009.

KRUSSER, Renata. Um olhar ergonômico para projetos de identidade visual. 2012. $105 \mathrm{f}$. Dissertação (Mestrado em Engenharia da Produção) - Universidade Federal de Santa Catarina, Florianópolis, 2002.

LACOMBE, Francisco; HEILBORN, Gilberto. Administração: Princípios e Tendências. São Paulo: Saraiva, 2003.

MANZINI, Ezio. Design para inovação social e sustentabilidade: comunidades criativas, organizações colaborativas e novas redes projetuais. Rio de Janeiro: E-Papers, 2008.

MANZINI, Ezio. Design, when everybody designs. An introduction to Design for Social Innovation. The MIT Press: Cambridge/London, 2015.

MORAES, Dijon. Design e complexidade. In: Moraes D. J; Krucken, L. (Org). Cadernos de estudos avançados em design: transversalidade. Barbacena: EdUEMG, 2016.

NORONHA, Raquel. Imaginar, materializar e jogar: correspondências entre o design e a antropologia e a prática projetual em jogos mediativos. In: Anais 30a Reunião Brasileira de Antropologia. João Pessoa, 2016.

Reason, P., Bradbury, H. The Sage handbook of action research, participative inquiry and practice. London: Sage, 2008.

SINGER, P. A recente ressurreição da economia solidária no Brasil. In: SANTOS, B. S. (org.) Produzir para viver: os caminhos da produção não capitalista. Rio de Janeiro: Civilização Brasileira, 2002.

TUNSTALL, E. Decolonizing design innovation: design anthropology, critical anthropology, and indigenous knowledge. In: GUNN, Wendy; OTTO, Tom; SMITH, R. C. Design Anthropology: Theory and Practice. p. 232-250. London: Bloomsbury, 2013. 